\title{
MILITARY ASPEGTS OF NARGOLEPSY, WITH REMARKS ON THE PATHOGENESIS OF NARCOLEPSY AND ON FATIGUE
}

\author{
BY \\ maX Levin, Harrisburg, Pennsyluania
}

INTRODUCTION

AN important by-product of Pavlov's work on cortical inhibition is the clarification of several hitherto puzzling problems of narcolepsy. I have already ${ }^{3}$ considered the significance of Pavlov's work for such 'major' phenomena of narcolepsy as cataplexy and sleep-paralysis and for such ' minor' phenomena as the occurrence of sleep attacks in situations in which the patient must bear pain without flinching. In the present paper I shall endeavour to interpret certain clinical phenomena occurring in soldiers.

It is assumed that the reader is acquainted with Pavlov's views on internal inhibition and sleep. Briefly stated, Pavlov found that he could cause a conditioned reflex to undergo internal inhibition by using one of four methods. (1) Experimental extinction: This refers to the " rapid and more or less smoothly progressive weakening of the reflex to a conditioned stimulus which is repeated a number of times without reinforcement' (Pavlov, p. 49). (2) Conditioned inhibition: This Pavlov defined as follows (p. 68): 'A positive conditioned stimulus is firmly established in a dog by means of the usual repetitions with reinforcement. A new stimulus is now occasionally added, and whenever the combination is applied, which may be at intervals sometimes extending to hours or days, it is never accompanied by the unconditioned stimulus. In this way the combination is gradually rendered ineffective, so that the conditioned stimulus when applied in combination with the additional stimulus loses its positive effect, although when applied singly and with constant reinforcement it retains its full powers.' (3) Delay : I omit giving details of this method. (4) Differentiation : E.g., a conditioned reflex is established to the tone of a tuning-fork of $\mathbf{8 0 0}$ double vibrations. The reflex having been established, it is now found that the tone of a fork of $812 \mathrm{~d}$. v. will also evoke the reflex. If now the 812 stimulus is repeatedly applied without reinforcement, and the 800 repeatedly with reinforcement, the animal in the course of time differentiates the two stimuli, with the result that the reflex appears in response to the 800 but not to the 812. Pavlov showed the latter stimulus to have acquired inhibitory properties.

Of momentous significance is the fact that Pavlov found that experimental conditions which produced internal inhibition also (in many cases) 
caused the animal to become drowsy and fall asleep (p. 251). He concluded that sleep is but widely irradiated internal inhibition.

\section{FALLING ASLEEP ON SENTRY DUTY}

The not infrequent occurrence of somnolence in sentries during the War aroused great curiosity among physicians. A common 'explanation' is that the sentry falls asleep because of the 'monotony' of his duties. This explanation, I shall try to show, puts the shoe on the wrong foot. One falls asleep, not ' because' of monotony, but because inhibition has irradiated over a sufficiently large part of the cortex. The environment, to be sure, is capable of checking this irradiation by bombarding one with excitatory (disinhibitory) stimuli. But to say that sleep is caused by insufficiency of excitation is as erroneous as to say that spasticity of the paralysed side in hemiplegia is caused by interruption of the pyramidal tract. Expressed properly, spasticity in hemiplegia represents the unopposed action of intact reflex arcs (Hughlings Jackson) ; similarly, falling asleep represents the unopposed spread of inhibition. We must therefore ask, does the work of a sentry favour the spread of inhibition? Consideration of the duties of a sentry will, I believe, show that this question must be answered in the affirmative.

Sentry duty constitutes a natural experiment which in all essential respects duplicates Pavlov's experiments on differentiation. The sentry has a conditioned defence reflex, describable thus : seeing (or otherwise perceiving) the enemy is followed by a response consisting either of aggressive movements or of movements serving to raise an alarm. The sentry must differentiate stimuli that really signify nearness of the enemy from those that represent only a 'false alarm.' He hears a faint rustling sound and ' is about to react' with a defence response; a moment later he realizes it was but the rustle of a nearby tree, whereupon a powerful inhibitory process checks the initial excitation. Let this happen a hundred times during the night and the cumulative effect of many inhibitory processes may well be such as to cause the soldier-especially if he have an unduly inhibitable cortex-to become irresistibly sleepy.

Using other words, we may say that sentry duty, necessitating an unusual degree of alertness, imposes an unusual strain on the cortex, thus encouraging cortical fatigue and its accompaniment, sleep.

\section{MORBID REACTIONS DURING BOMBARDMENT}

MacCurdy, ${ }^{4}$ in his admirable article on War Neuroses, alluded to certain symptoms that are of the utmost importance for us here. I quote in full a paragraph beginning on the 16th page of his article (this paragraph describes the reactions of recruits to their first bombardment) : 'The first actual trial which the recruit usually meets is the experience of being shelled. Naturally 
the intensity of the bombardment varies greatly, and if the shells are falling at long intervals of time and at considerable distance, it is only the most unstable who are particularly affected. Few, if any, as far as one can learn, are absolutely normal on introduction to a heavy bombardment. By far the commonest response is one of fear, usually accompanied with the idea of running away, which the subject himself sees to be absurd. Although the men may make an effort to hide the signs of this fear, they are so frequently evident under initial shelling that the military authorities count on their appearance. Their presence at this time is no indication of the degree of indifference which may later develop. A less common reaction is that of cxcitement, accompanied even with a kind of spurious elation. The man has a tendency to make facetious remarks about the shells, to laugh at feeble witticisms, and very often feels under considerable motor tension, there being a pressing desire to do something, to do it immediately and do it hard. A still more unusual but very interesting reaction is that of slowness or languor (which may succeed primary fear). This may be accompanied by a depressive affect or by lethargy so extreme that the individual will lie down and go perforce to sleep with a pathological indifference to the danger' (italics mine).

Let us consider these phenomena from the viewpoint of Pavlov's work. When shells are falling about us, the 'natural tendency' is to run away-a tendency which is suppressed because of the desire not to appear a coward. This situation offers us a perfect instance of conditioned inhibition : an action which is permissible when the stimulus consists just of flying missiles (e.g., when dynamite explodes near us in civil life) becomes forbidden when, so to speak, the stimulus consists of flying missiles plus the environment of a battlefield. When we consider the strength of the defence reflex to pain, we may plausibly suppose that it is a powerful inhibitory process that keeps soldiers from running away at their first bombardment. Herein, I believe, lies the explanation of the somnolence noted by MacCurdy in some soldiers.

MacCurdy found that some soldiers, instead of being sleepy, reacted with 'a kind of spurious elation,' with a tendency to 'laugh at feeble witticisms,' etc. These phenomena are, I submit, due to inhibition of the highest layers of the highest centres (Hughlings Jackson), and bear the same relation to somnolence that the elation of the mildly intoxicated man bears to the stupor of the profoundly intoxicated man. In discussing the problem of varying depths of dissolution, Jackson argued that a small dose of alcohol paralyses only the highest layer of the highest centres, leaving the subject comparatively competent but lacking self-control, wherefore he is elated and extravagant; a very large dose paralyses all of the highest centres and some of the lower centres as well, leaving the subject very incompetent. We may justly argue by analogy that in the spuriously elated soldier there is inhibition limited to the topmost layers of the highest centres, while in him who falls asleep during bombardment there is much more widespread inhibition. This statement accords with MacCurdy's observation that spurious elation is a 
commoner reaction than somnolence: we may rightly expect the milder form of a morbid phenomenon to occur more commonly than the advanced form.

I digress to call attention to several cases of narcolepsy in which, in civil life, the patient fell asleep in situations in which he must have been conscious of danger. Hilpert's patient fell asleep while working on a scaffold, as did also the patient in Spiller's Case I. In Spiller's Case II the patient, a locomotive fireman, fell asleep ' while holding on to the grabirons of a train said to be moving at a speed of about 70 miles an hour.' In Wilson's Case I the patient, a railway carpenter, had a sleep attack ' when actually on the top of a signal post executing a repair.' In these cases we may say that the ' natural tendency' to escape from a position of danger was inhibited, as a result of which the (easily inhibitable) brain of the patient underwent widespread inhibition. The mechanism provocative of sleep attacks in the four patients cited in this paragraph seems identical with that operative in the soldiers who fell asleep during their first bombardment.

In my former paper ${ }^{3} \mathrm{I}$ considered two cases in which the patient fell asleep while suffering pain. One was a narcoleptic patient of mine who fell asleep while the dentist was drilling his teeth; the other was a patient of Gowers' who fell asleep while a probe was being passed down a nasal fistula. I pointed out that the significant feature of these cases was that the patients, as self-respecting adults, were obliged to bear the pain without flinching, i.e., they had to suppress their defence reflex to pain. I also alluded to one of Rothfeld's cases, in which the voluntary suppression of sexual reflexes precipitated an attack of a certain form of ' localized sleep.' We may make the general statement that in persons with easily inhibitable brains the voluntary suppression of powerful reflexes may cause the appearance of localized or generalized sleep. All the cases mentioned in this section represent special instances of this general phenomenon.

\section{FATIGUE}

MacCurdy called attention to the fact that war neuroses were unknown prior to the era of modern trench warfare, and concluded that the latter is a necessary cause of the former. In analysing the nature of modern warfare, he said (p. 12): "Anyone who is at all familiar with the phenomena of modern trench warfare can see that it makes a great demand on the devotion of the belligerents and offers little personal satisfaction in return. In previous wars the soldiers, it is true, were called upon to suffer fatigue and expose themselves to great danger. In return, however, they were compensated by the excitement of more active operations, the more frequent possibility of gaining some satisfaction in active hand-to-hand fighting, where they might feel the joy of personal prowess. Now, the soldier must remain for days, weeks, even months, in a narrow trench or a stuffy dugout, exposed to a constant danger of the most fearful kind, namely, bombardment with high explosive shells which 
come from some unseen source, and against which no personal agility or wit is of any avail. This naturally occasions great fatigue, and, on the other hand, opportunities of active hand-to-hand fighting are rare, so that a man may be exposed for months to the appalling effects of bombardment and never once have a chance to retaliate in a personal way. Consequently the sublimations described above are more difficult to maintain than in any previous war. The soldier becomes fatigued ....'

MacCurdy wrote this 10 years before Pavlov's work became generally known in western Europe, and it is remarkable that he surmised, between fatigue and the suppression of the instinct for hand-to-hand fighting, a relationship which Pavlov's work plausibly explains. Being at the front arouses in the soldier the 'primitive expectation' of physically meeting an antagonist, exactly as in an appropriately trained dog the sound of a metronome arouses the expectation of a dish of meat. When in the dog the conditioned stimulus is no longer reinforced (i.e., when the sound of the metronome is no longer followed by the presentation of meat), an inhibitory process occurs and the conditioned reflex undergoes ' experimental extinction' (i.e., the sound of the metronome no longer excites the flow of saliva). These conditions are duplicated in the case of the soldier, who, in spite of his 'primitive expectation,' has no physical meeting with an antagonist. In consequence, just as in the dog the flow of saliva is inhibited, so in the soldier the movements of hand-to-hand fighting are inhibited. Since dogs, during experimental extinction, frequently get drowsy and fall asleep, we may attach significance to the occurrence of fatigue in soldiers under like conditions; fatigue under these conditions is a manifestation of inhibition.

Both military and civil life offers countless situations in which one must suppress strong impulses. The impulse to run away during bombardment has already been alluded to. MacCurdy was impressed by the apparent importance, as a fatigue-provoking factor, of the situation of the soldier or officer who finds himself under an antagonistic or incompetent superior whose unfair or unwise orders he may not question (see, e.g., his Cases X and XI). In this situation the soldier must suppress his impulse to protest, exactly as during bombardment he must suppress his impulse to run away. As a civil counterpart, I cite the instance of a clergyman of 65, a man of unusual physical and mental vigour. (He consulted me for no infirmity and I know him only as a friend.) A man of great integrity, he finds among his parishioners much hypocrisy, which he would vigorously denounce if he were financially independent. $\mathrm{He}$ has repeatedly observed that after a sermon touching on topics which more than ordinarily stimulate his denunciatory impulses, thus necessitating on his part an unusual effort at suppression, he is fatigued to the point of exhaustion, while on the other hand a brisk five-mile walk, which he takes daily, causes, in spite of his age, almost no fatigue.

In the cases cited in the last paragraph, we deal with conditioned 
inhibition. The mechanism of these cases differs from that of the soldiers who lack an outlet for their impulse for hand-to-hand fighting.

MacCurdy observed that 'the first sign of an approaching neurosis is fatigue' (p. 18). We may therefore regard fatigue as a relatively mild clinical manifestation of inhibition.

I beg the reader to note that I make no general statement about all cases of fatigue, but assert only that in some cases it seems proper to regard fatigue as a manifestation of cortical inhibition produced by mechanisms identical with those revealed by Pavlov's experiments.

\section{HYPNAGOGIC HALLUGINATIONS}

MacCurdy found that the early stages of war neuroses were characterized, in addition to diurnal fatigue, by hypnagogic hallucinations. He wrote (p. 20): 'There is great difficulty in getting to sleep, with a long period of hypnagogic hallucinations. Whatever has been the dominating experience of the day appears in troublesome vision before the eyes of the soldier, who, although knowing that what he sees is not actually there, is still unable either to go to sleep or to awaken himself sufficiently to banish the visions.'

To discuss adequately the physical processes concomitant with hallucinations would carry us beyond the scope of this paper. It will suffice to say that there is good reason to believe that hypnagogic hallucinations indicate a partial inhibition of the cortex. I have already called attention ${ }^{3}$ to the remarkable frequency with which hallucinations occur during sleep-paralysis, a state in which the patient, on falling asleep or awaking from sleep, is conscious but paralysed. In sleep-paralysis without hallucinations, inhibition is localized in the motility substrate, the 'substrate of consciousness' being (so far as we can now determine) free of inhibition; in sleep-paralysis with hallucinations there is, besides the complete inhibition of the motility substrate, partial inhibition of the substrate of consciousness (not complete inhibition of the substrate of consciousness, because in that case the patient would be fully unconscious, i.e., asleep). Hypnagogic hallucinations in the soldier at the front are, therefore, cognate to diurnal fatigue, in that both phenomena are manifestations of inhibition.

The reader may ask, Since it is claimed that trench warfare encourages cortical inhibition, and since inhibition and sleep are manifestations of the same thing, why does not the neurotic soldier sleep soundly at night instead of poorly? The answer to this question is for the present unknown, as is also that to the question of why narcoleptics in civil life so often sleep poorly at night, contrary to the expectation that because they suffer from somnolence they will therefore sleep unusually soundly.

\section{INHIBITORY PHENOMENA BEHIND THE BATTLE-FRONT}

While the battle-front offers the easiest opportunities for the production of inhibition, military service behind the front is not without such opportuni- 
ties. Collins' Case I, in which the patient's narcolepsy began while he was in the army, shows remarkably well the apparent relationship that may exist between military service and narcolepsy. Because of its great interest I cite Collins' description of the origin of his patient's symptoms : ' $\mathrm{He}$ noticed that while drilling he would become very tired. As time went on he would fall over while drilling because of extreme weakness in his muscles. When he went in for mess at noon he would fall asleep and it was with the greatest difficulty that the sergeant could awaken him for afternoon duty.'

It is obvious that on entering the army the recruit must radically alter the whole mode of his life, i.e., he must discard (inhibit) many of the conditioned reflexes of civil life and acquire many new ones. Thus the responses of the recruit to the commands of the drill-sergeant represent a set of conditioned reflexes. Now, in addition to the four methods whereby Pavlov found he could artificially induce inhibition, there is a spontaneous inhibition which conditioned reflexes undergo even when they are regularly reinforced. According to Pavlov (p. 234), ' one of the most important' properties of cortical cells is that ' under the influence of conditioned stimuli they pass, sooner or later, into inhibition.' After citing a number of experiments, he stated (p. 244): 'The fundamental fact in all these experiments . . is the transition sooner or later into inhibition of the state of the cortical elements acted upon by the conditioned stimulus. So far as concerns all the experimental evidence at our disposal up to the present, this transition must be regarded as depending on a functional exhaustion of the cortical elements as a result of their activity in response to a stimulus.' It is therefore understandable that long daily drill-periods continued for many months should encourage the occurrence of inhibitory phenomena, and the onset of narcolepsy during a period of military training in Collins' case should not be hastily dismissed as a coincidence.

Should there be another war, it would be desirable to study carefully the relation of narcolepsy to military service. It would be desirable to ascertain how many cases begin in training, and how soon after entrance into the army they begin. It would be desirable to make a careful study of fatigue, morbid elation, hypnagogic hallucinations, nocturnal restlessness, cataplexy, sleep-paralysis and morbid somnolence, with especial attention to the types of situation that seem to encourage the appearance of these phenomena.

\section{SUMMARY}

Certain situations in military life constitute natural experiments in which are duplicated the essential conditions of Pavlov's laboratory experiments on internal inhibition. Some of these situations are : (1) trench warfare, in which the impulse for hand-to-hand fighting is inhibited ; (2) bombardment, in which the impulse to run away is inhibited ; (3) sentry duty, in which the sentry must differentiate insignificant stimuli from those that indicate the 
approach of the enemy. The occurrence of narcoleptic symptoms in response to these situations is a phenomenon identical with the occurrence of inhibition and sleep in Pavlov's corresponding experiments. Consideration is given to the occurrence, in these situations, of morbid somnolence, hypnagogic hallucinations, fatigue and morbid elation.

\section{REFERENGES}

1 Collins, H. A., 'Ephedrine in the treatment of narcolepsy,' Ann. of Int. Med., $1932,5,1289$.

2 Hilpert, P., ' Ueber einen Fall von Narkolepsie,' Klin. Woch., 1925, 4, 1553.

${ }^{3}$ Levis, M., 'The pathogenesis of narcolepsy, with a consideration of sleep-paralysis and localised sleep,' Jour. Neurol. and Psychopath., 1933, 14, 1.

4 MacCurdy, J. T., 'War neuroses,' Psychiatric Bulletin, July 1917.

5 Pavlov, I. P., Conditioned Reflexes, 1927.

' Spiller, W. G., ' Narcolepsy occasionally a postencephalitic syndrome,' Jour. Amer. Med. Assoc., 1926, 86, 673.

' Wilson, S. A. K., 'The narcolepsies,' Brain, 1928, 51, 63. 